\title{
INFLUENCE OF AIR DISTRIBUTION IN MODERN LARGE UNIVERSITY LECTURE HALL ON THERMAL COMFORT
}

\author{
MÁRIA BUDIAKOVÁ \\ Faculty of Architecture, Slovak University of Technology in Bratislava, Nám. slobody 19, 81245 Bratislava, Slovakia \\ E-mail: budiakova@fa.stuba.sk
}

\begin{abstract}
The paper is focused on the influence of air distribution in modern large university lecture hall on the thermal comfort. Providing the optimal parameters of the thermal comfort in the interiors of a university is immensely important for the students. Meeting these parameters is inevitable not only from physiological point of view but also to achieve the desirable students' performance. Parameters of the thermal comfort are also influenced by air distribution system in large university lecture hall. Correct position of supply air and extract air is very important. Experimental measurements of thermal comfort were carried out in the winter season in the large lecture hall of Vienna University of Economics and Business. The device Testo 480 was used for the measurements. Obtained values of air temperature, air relative humidity, air velocity, globe temperature, indexes PMV and PPD are presented in the charts. Modern air distribution system and air conditioning system of the large university lecture hall were evaluated on the basis of thermal comfort parameters. Conclusion of this paper states the principles of how to design modern air distribution systems and air conditioning systems in the new large university lecture halls.
\end{abstract}

Keywords: thermal comfort, air distribution systems, air conditioning systems

\section{Introduction}

Air distribution system of air conditioning system or mechanical ventilation system in large university lecture halls with big amount of students have influence on multiple parameters of the thermal comfort [1]. Position of supply air and extract air, direction of airflow and air velocity in large university lecture halls influence selected parameters of the thermal comfort [2]. Incorrectly designed position of supply air and extract air, and excessive air velocity may cause disruption of the thermal comfort and formation of local thermal discomfort [3].

Providing the thermal comfort in the large university lecture hall is very important because students spend the majority of their time in school in the schoolrooms. Thermal comfort in the small university lecture hall is defined as the state of mind that expresses satisfaction with the surrounding environment. The fundamental quantities for the evaluation of the thermal comfort are internal air temperature, operative temperature, globe temperature, air relative humidity and air velocity [4]. Then the thermal comfort is evaluated with index PMV (Predicted mean vote) and index PPD
(Predicted percentage dissatisfied) [5, 6]. Not fulfilling the parameters of the thermal comfort in the large university lecture hall contributes to the high sickness rate of students, especially in the winter [7,8].

The local thermal discomfort might arise when the parameters and air elements of air conditioning system or mechanical ventilation system are incorrectly designed. The incorrect operation of ventilation system might also contribute to its creation. Local thermal discomfort (the thermal dissatisfaction) can also be caused by unwanted cooling or heating of one particular part of the body [9]. The most common cause of the local thermal discomfort is the draught but local discomfort can also be caused by an abnormally high vertical temperature difference between head and ankles, by too warm or too cool floor, or by too high radiant temperature asymmetry. People are most sensitive to radiant asymmetry caused by a warm ceiling, a cool wall (windows, glazed facade), a cool ceiling or by a warm wall. The major problem in the large university lecture hall is the draught that is caused by incorrect position, distance of supply air and extracts air from the floor, and the incorrect velocity of the air flow.

This is an open-access article distributed under the terms of the Creative Commons Attribution-NonCommercial 4.0 International License (https://creativecommons.org/licenses/by-nc/4.0/), which permits unrestricted use, distribution, and reproduction in any medium for non-commercial purposes, provided the original author and source are credited, a link to the CC License is provided, and changes - if any - are indicated. 


\section{Analysis of air distribution systems of large university lecture halls}

One of the important factors of air conditioning system or mechanical ventilation system in large university lecture hall is the correct air distribution system [10]. Students have to feel pleasantly warm without the feeling of draught. Therefore, besides the air temperature and air velocity in air vents the position of supply air and extract air in large university lecture hall is very important [11]. The most suitable solution is the air distribution from the bottom towards the top, which must be considered in architectural design of the interior of large university lecture hall. During this air distribution, air velocity in vents for supply air can be very low and thus a sitting student does not have a feeling of draught. It is not suitable to install inversely oriented air distribution from the top towards the bottom inside of modern university lecture halls. Also, the air distribution from the front to the back wall is not suitable. In both unsuitably distributed directions of air, a high air velocity is created in the place of students' seating which causes the feeling of draught, dis-

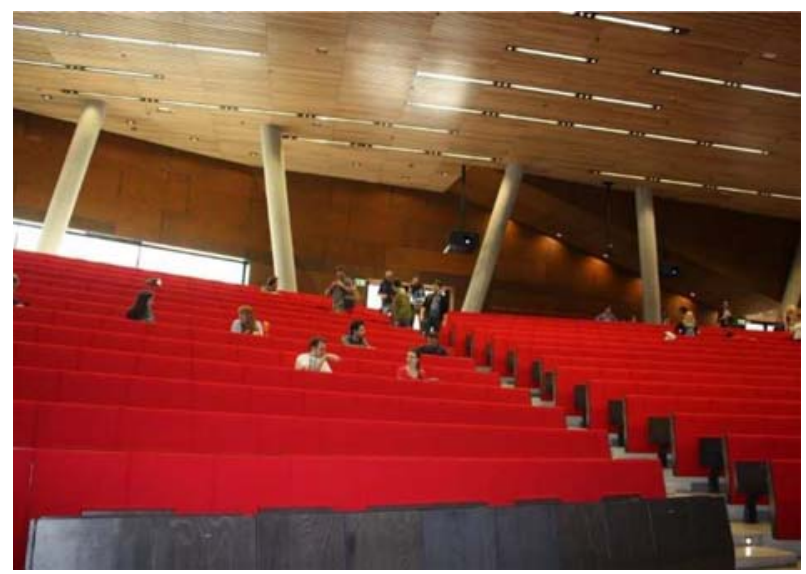

Fig. 1. Main large lecture hall of Vienna University of Economics and Business

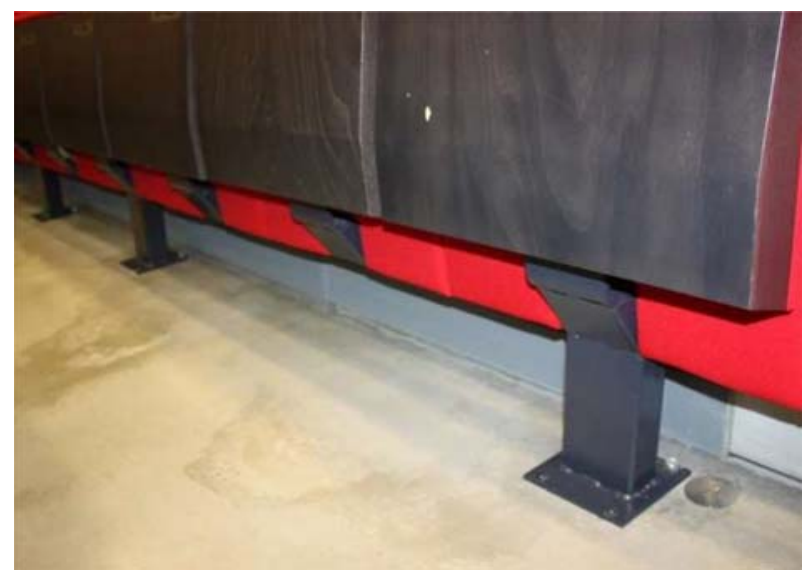

Fig. 2. Rectangular continuous vents for supply air in the stepped floor satisfaction and worse concentration during the lecture. Therefore, the mutual interaction between architectural design and placement of vents for supply air in university lecture hall was closely analysed. The air distribution from the bottom to the top was analysed. Most often, the vents for supply air in university lecture hall are located in the stepped floor which is built because of stepped seating.

Many modern large university lecture halls were analysed in terms of air distribution system. Particular examples of modern large university lecture halls were closely analysed in terms of placement of vents for supply air. The air distribution from the bottom to the top was analysed. Most often, the vents for supply air in large lecture hall are located in the stepped floor which is built because of stepped seating. From all of the analysed large university lecture halls, the main hall of Vienna University of Economics and Business was chosen for the research purposes, Fig. 1. Figure 2 depicts the position of rectangular continuous vents for supply air in the stepped floor in the large lecture hall of Vienna University of Economics and Business. It is main large lecture hall which has interior significantly segmented. The interior is harmonized with the continuous vents for supply air in the stepped floor. Shape of the hall is significantly segmented which is harmonized with vents for supply air in stepped floor. Modern look of large lecture hall is harmonized with unobtrusive and modern vents for supply air, which does not disturb architectonic appearance of the interior. Suppressed design of vents for supply air contrasts interestingly with bright red armrests and seats. Vents for extract air are placed under the wooden slotted ceiling. In the back glassed wall, window sill fan coil units are placed creating continuous strip, Fig. 3.

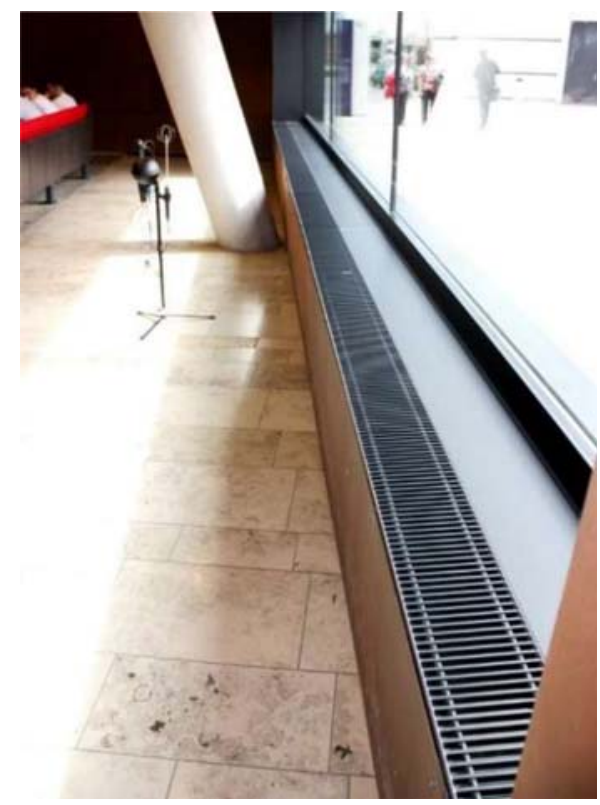

Fig. 3. Window sill fan coil units in the back glassed wall 


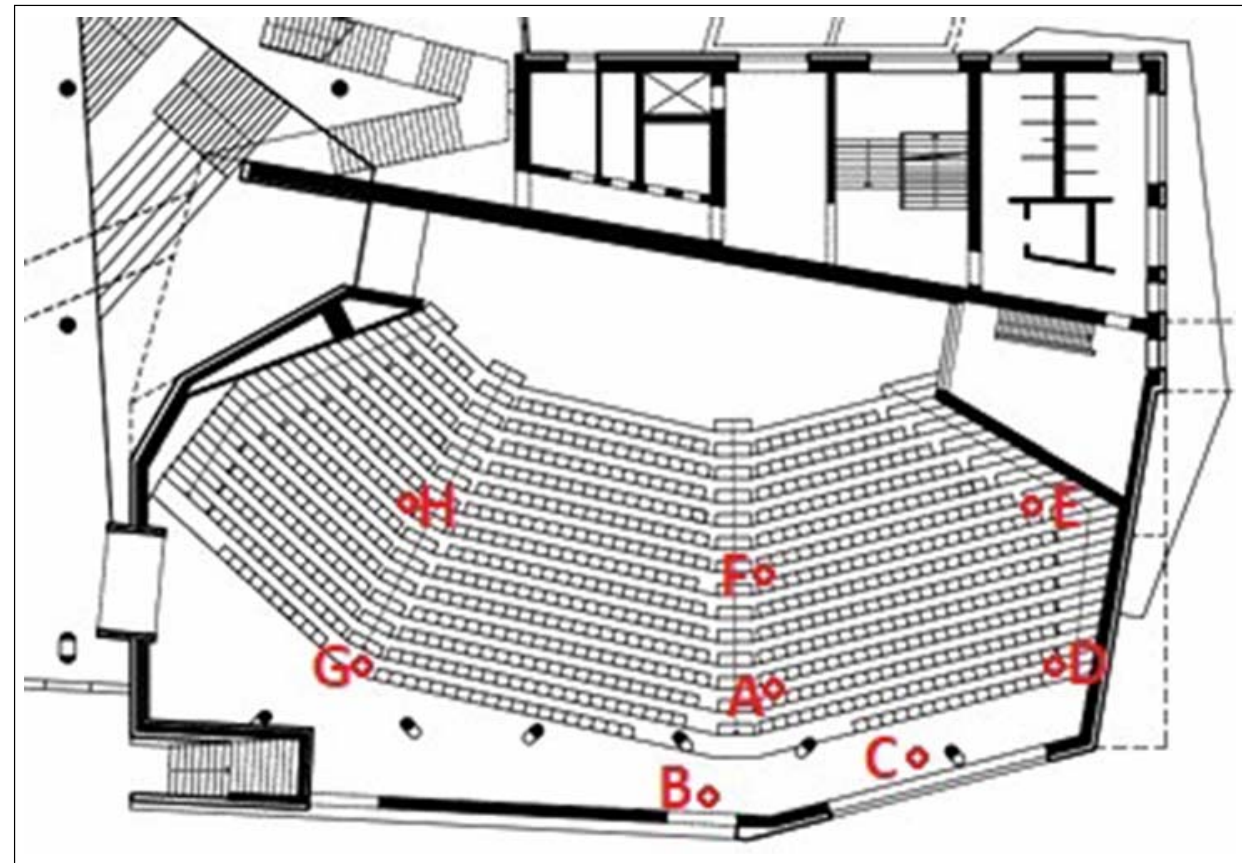

Fig. 4. Ground-plan of large university lecture hall with standpoints

\section{Methodology of experimental measurements}

Experimental measurements were carried out in the large university lecture hall - Figure 1 at the Vienna University of Economics and Business in the end of March. The aim of the measurements was to record the parameters of the thermal comfort: air temperature, air relative humidity, air velocity, index PMV and index PPD.
The measurements were carried out in the large university lecture hall in eight standpoints in the height of $1.1 \mathrm{~m}$ above the floor level, Fig. 4. Standpoint A was in the right segment of the seating, in the third row from above on the left side near aisle, Fig. 5a. Standpoint B was in the middle of the back door which leads to the exterior, Fig. 5b. Standpoint $C$ was in the middle of the back glazing, Fig. 6a. Standpoint $\mathrm{D}$ was in the right segment of the seating in the last row on the right side near aisle, Fig. 6b. Standpoint E
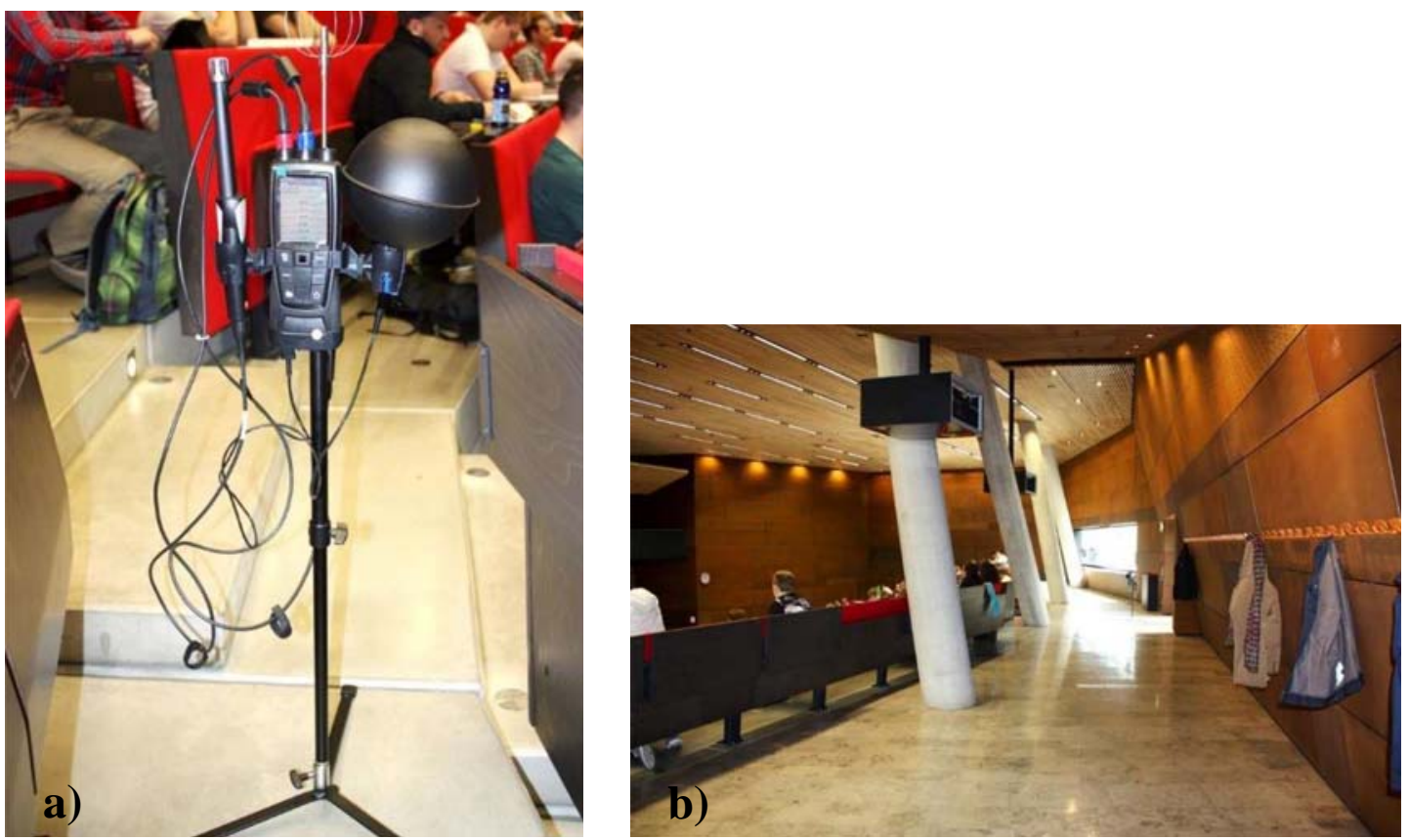

Fig. 5. Measurements in standpoint A and standpoint B 

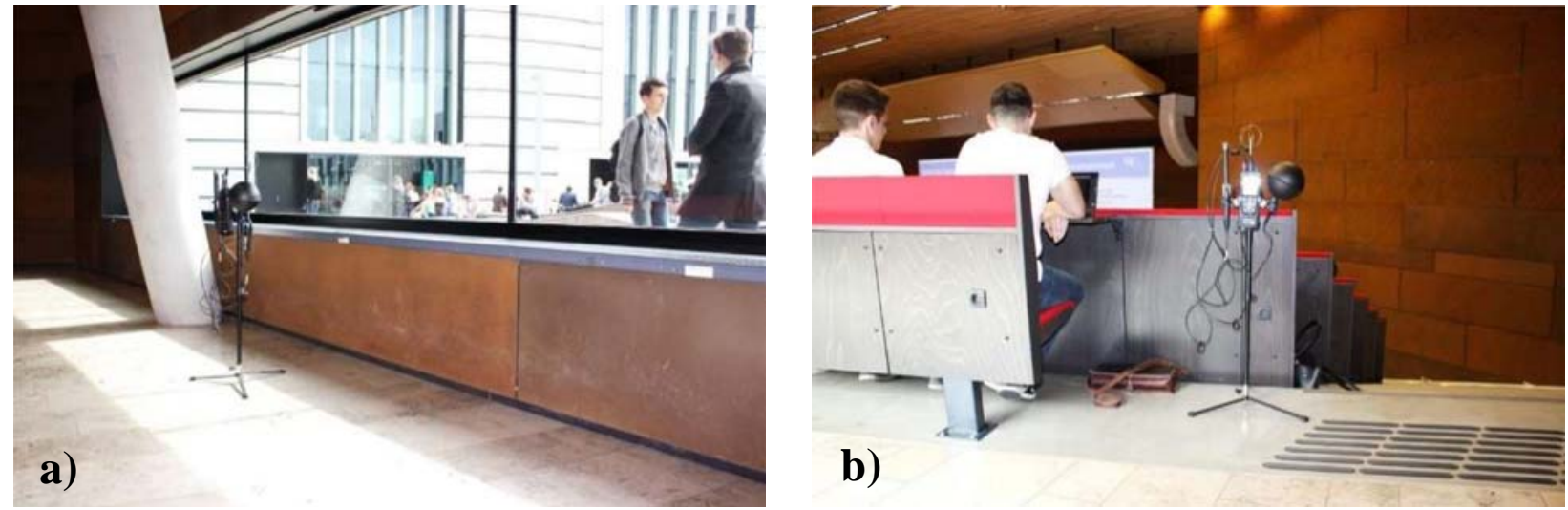

Fig. 6. Measurements in standpoint $\mathrm{C}$ and standpoint $\mathrm{D}$
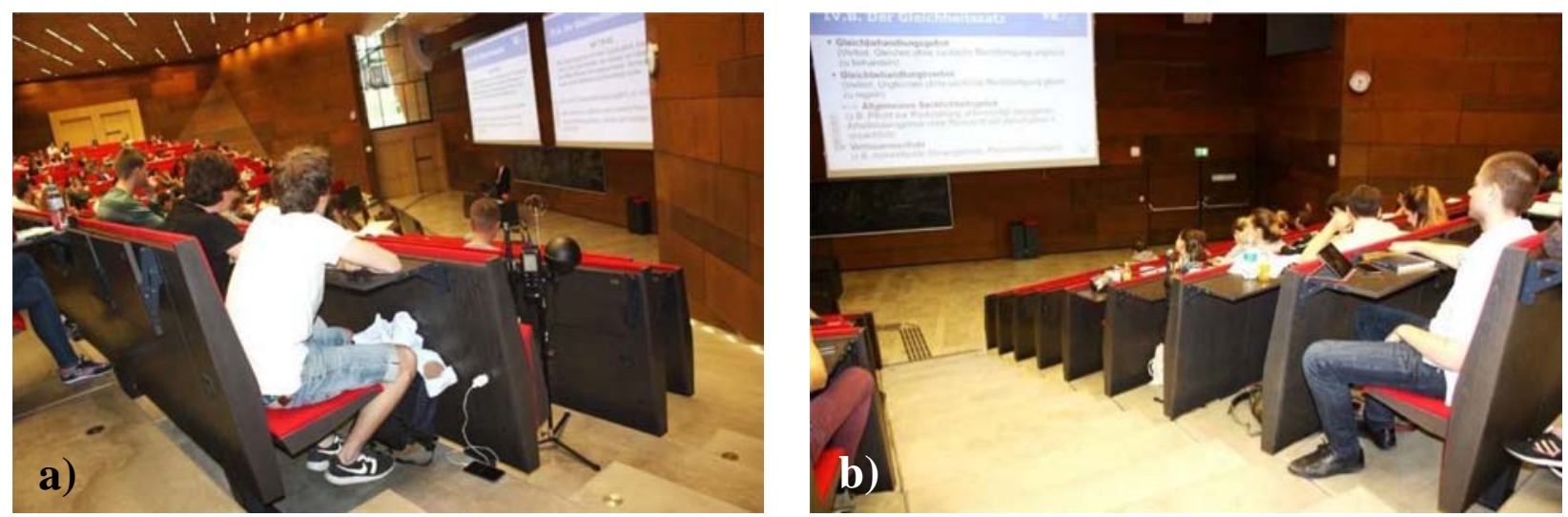

Fig. 7. Measurements in standpoint $\mathrm{E}$ and standpoint $\mathrm{F}$
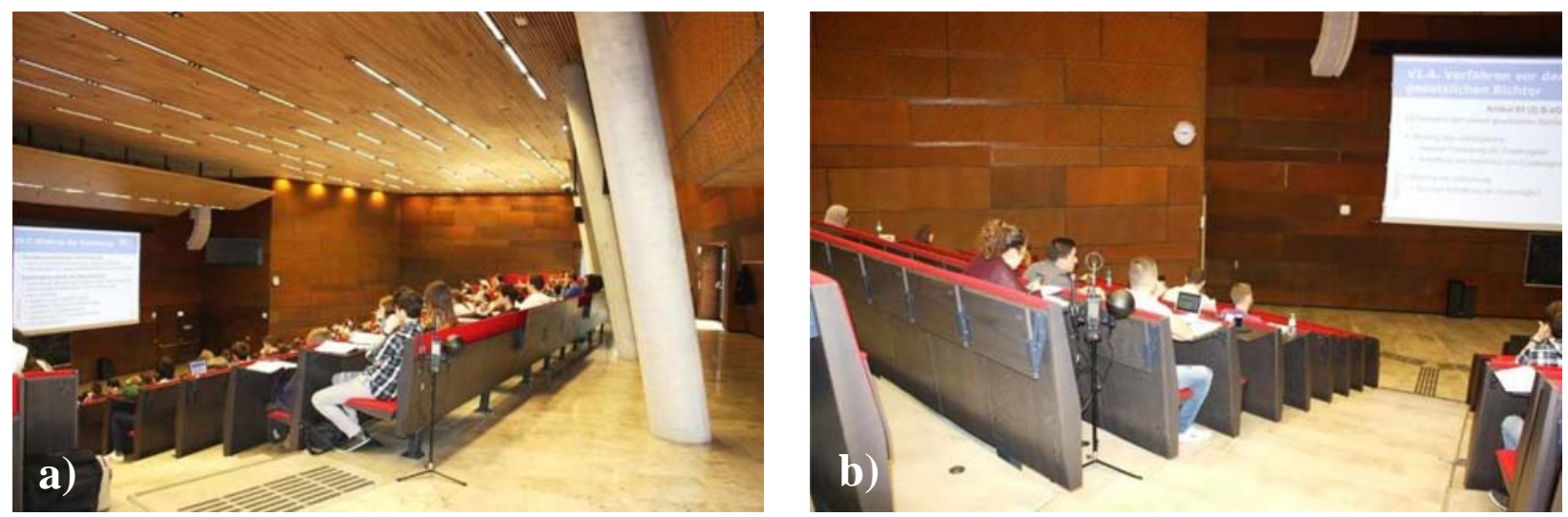

Fig. 8. Measurements in standpoint $\mathrm{G}$ and standpoint $\mathrm{H}$

was in the right segment of seating in the seventh row (centre) on the right side near aisle, Fig. 7a. Standpoint $\mathrm{F}$ was in the right segment of seating in the seventh row (centre) on the left side near aisle, Fig. 7b. Standpoint G was in the central segment of seating in the last row on the left side near aisle, Fig. 8a. Standpoint $\mathrm{H}$ was in the left segment of seating in the eighth row (centre) on the right side near aisle, Fig. 8b.
The parameters of the thermal comfort were recorded with the device Testo 480. Input data in measurements were: metabolic rate $1.0 \mathrm{met}$, clothing insulates 1.0 clo. Twenty measurements with time delay (one by one) were carried out in each standpoint. Statistical mean was calculated from measured values. Measurements were carried out one by one in individual standpoints. Outdoor air temperature and air relative humidity were measured and recorded by the separate 
device. Outdoor air temperature increased from value $20.1^{\circ} \mathrm{C}$ to value $21.8^{\circ} \mathrm{C}$. Outdoor air relative humidity decreased from the value $48.1 \%$ to the value $45.2 \%$.

\section{Results and analysis of measurements}

Figure 9 shows the values of air temperature in the height of $1.1 \mathrm{~m}$ above the floor level in all standpoints. In standpoints $\mathrm{A}$ and $\mathrm{B}$, the air temperature was increased which was caused by insulation through glazing in the back part of large university lecture hall. Air temperature in standpoint $\mathrm{C}$ was the highest and in standpoint $\mathrm{D}$, it was very high meaning that the values in both standpoints were inadmissibly high. Standpoint $\mathrm{D}$ was the most critical since it is the place of students' seating. The architectural act to open part of the back wall of the lecture hall and place there glazing is questionable. The intention of the architect to create visual contact between students passing by and the action in the lecture hall is evident but it is questionable in terms of ensuring thermal comfort. Technically, it would be needed to create independent regulated air-conditioned zone for the last four rows of seating on the right side. This zone would be regulated depending on insulation. It is obvious from this example that mutual cooperation of specialists of these two professions has not brought desired effect. The HVAC (heating, ventilating, air conditioning) designer would be needed who is able to perceive modern architectural challenges and is also able to react on them with technology. On the other hand, there should be an architect who is significantly more educated in technology. In standpoints E, F, G, H, the values of air temperature were slightly increased but the values among themselves were relatively equal. This balance of values shows that this modern air conditioning system of large university lecture hall is suitable and the design of big part of the interior was technically well designed.

The values of air velocity in the height of $1.1 \mathrm{~m}$ above the floor level in all standpoints were in range of values 0.00 and $0.02 \mathrm{~m} \cdot \mathrm{s}^{-1}$, which means satisfactory values. It confirms the suitability of air conditioning system with vents for supply air in the stepped floor.

Figure 10 shows the values of air relative humidity in the height of $1.1 \mathrm{~m}$ above the floor level in all

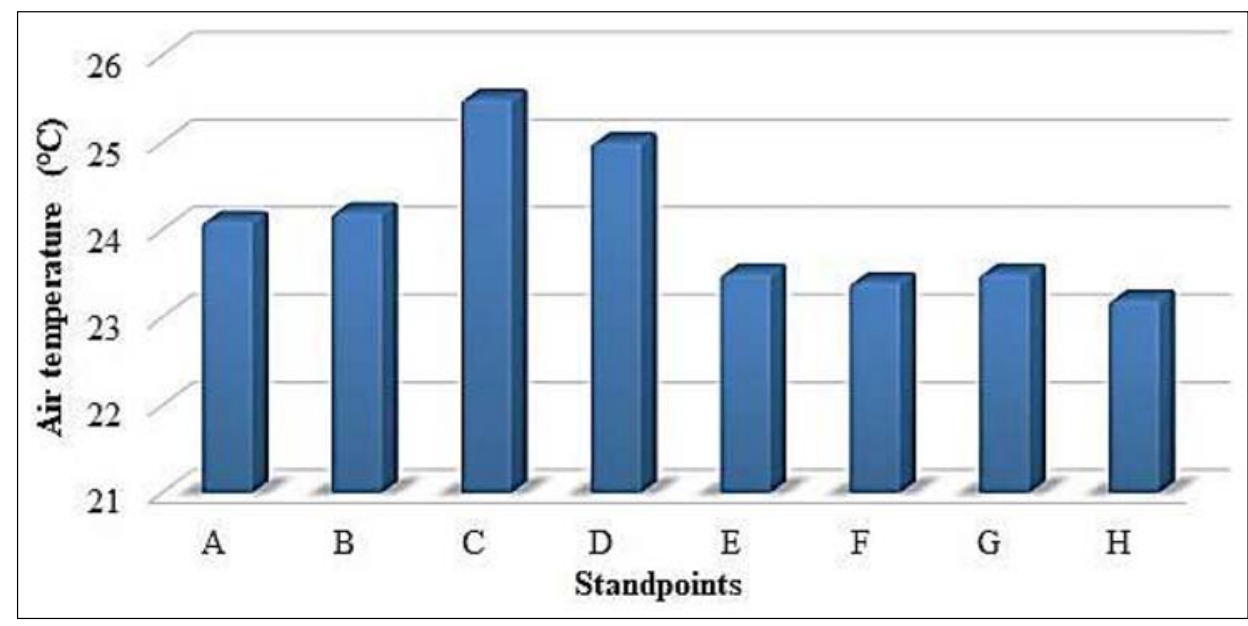

Fig. 9. Values of air temperature in all standpoints

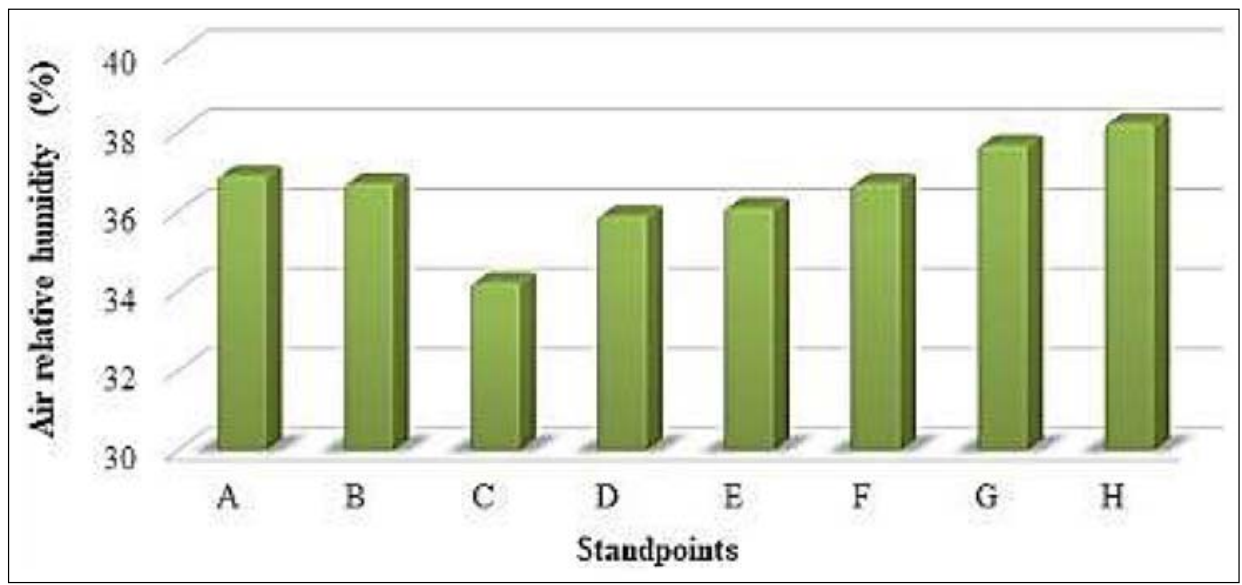

Fig. 10. Values of air velocity in all standpoints 


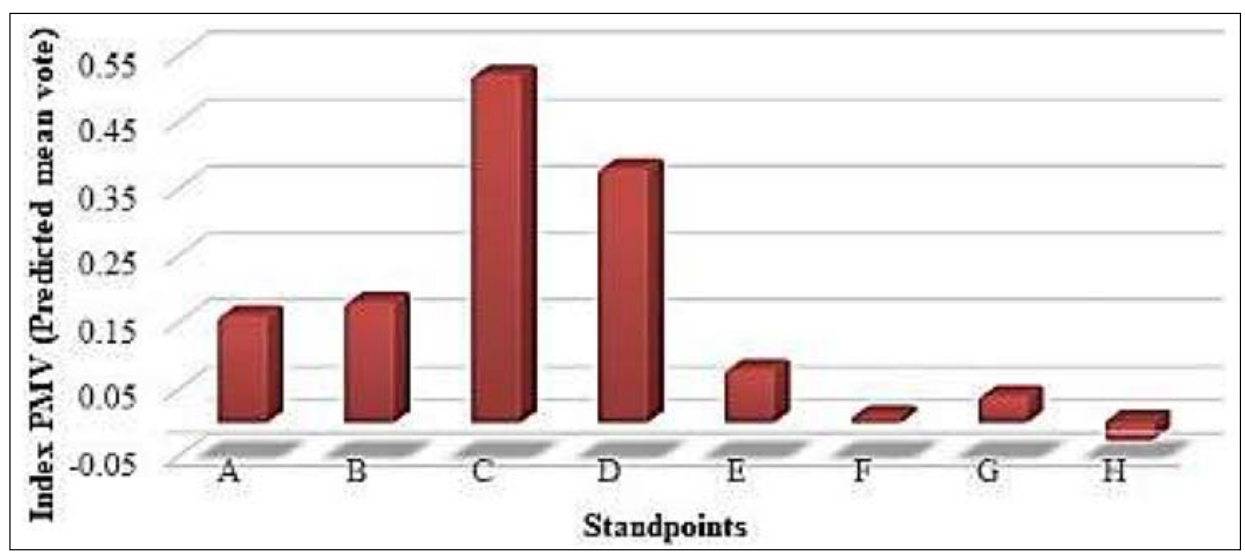

Fig. 11. Values of index PMV in all standpoints

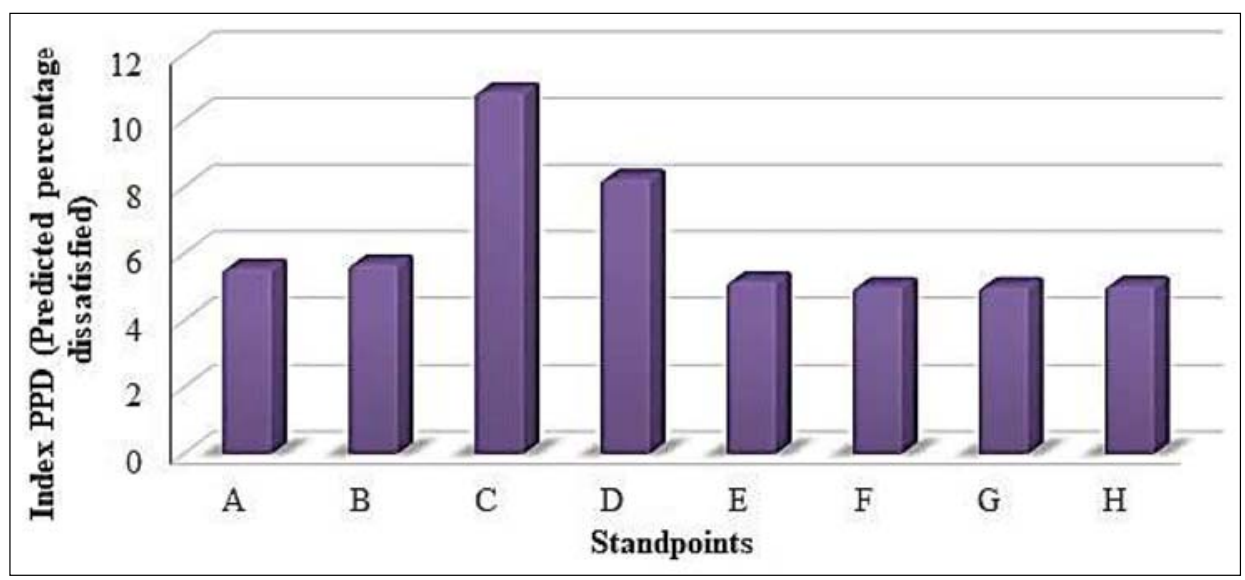

Fig. 12. Values of index PPD in all standpoints

standpoints. Optimal value of air relative humidity is around $40 \%$, suggested value is $50 \%$. Health problems arise if the relative humidity decreases to $20 \%$ or exceeds $60 \%$. The values of air relative humidity were acceptable; to achieve optimal values, it would be needed to slightly moisture the air. The lowest value is in standpoint $\mathrm{C}$ where students do not sit. There are no vents for supply air; therefore the air exchange is minimal there.

Figure 11 shows the values of index PMV in the height of $1.1 \mathrm{~m}$ above the floor level in all standpoints. The highest value of index PMV was in standpoint $\mathrm{C}$; it was caused by insolation through glazed surface - students do not sit here so it is not a problem. The second highest value was in standpoint D where students sit; it was also caused by insulation. This value is considered as bearable; it can be improved by creating independently regulated air-conditioned zone for last four rows of seating on the right side. This solution would also help in standpoint A. In standpoints E, F, $\mathrm{G}, \mathrm{H}$ where students were sitting, the values were in range of optimal values, which confirms the quality of air conditioning system.

Figure 12 shows the values of index PPD in the height of $1.1 \mathrm{~m}$ above the floor level in all standpoints.
In the place of students' seating, the highest value of index PPD was in standpoint D; this can be improved by creating independent air-conditioned zone.

\section{Conclusion}

Ensuring optimal values of parameters of the thermal comfort in large university lecture hall is very important for students. Scientific analysis showed that the most modern large university lecture halls use vents for supply air in the stepped floor. Experimental measurements showed suitability of this air conditioning system for large university lecture halls. Parameters of thermal comfort in large part of university lecture hall were satisfactory. The problem arose by modern, atypical, architectural touch in the back part of the lecture hall where the large glazed surface was built. Insolation on this glazed surface significantly influenced parameters of thermal comfort in the last rows of students' seating which are in front of the glazing. This modern, architectural intention created visual contact between students passing by and the action in the lecture hall but it was not thought-out in terms of thermal comfort. In this case, the solution would be to create independently air-conditioned zone for the last four 
rows of seating on the right side which would be regulated depending also on the insolation. In general, it can be stated that an HVAC designer should undergo more education to tackle modern architectural challenges. On the other hand, an architect should be significantly more educated in technology.

\section{References}

[1] Awbi H. B. (1991), Ventilation of Buildings. E \& FN Spon, London

[2] Santamouris M. (2006), Ventilation for Comfort and Cooling. Earthscan, London

[3] Seppänen, O. (2003), The Effect of Ventilation on Health. Earthscan, London

[4] Bánhidi L., Kajtár L. (2000), Komfortelmélet (Comfort Theory). Múegyetemi Kiadó, Budapest

[5] STN EN ISO 7730 (2006), Ergonomics of the thermal environment - Analytical determination and interpretation of thermal comfort using calculation of the PMV and PPD indices and local thermal comfort criteria. Slovak Office of Standards, Metrology and Testing, Bratislava

[6] STN EN ISO 7726 (2003), Ergonomics of the thermal environment. Instruments for measuring physical quantities. Slovak Office of Standards, Metrology and Testing, Bratislava.

[7] Etheridge D. (2011), Natural Ventilation of Buildings. John Wiley \& Sons, Chichester

[8] Jokl M. (2002), Zdravé obytné a pracovní prostředí (Healthy Living and Working Environment). Academia, Praha

[9] STN EN 15251 (2008), Indoor environmental input parameters for design and assessment of energy performance of buildings addressing indoor air quality, thermal environment, lighting and acoustics. Slovak Office of Standards, Metrology and Testing, Bratislava

[10] Heiselberg P. (2006), Hybrid Ventilation in Non-Residential Buildings. Earthscan, London

[11] Witthauer J., Horn H., Bischof W. (1993), Raumluftqualität. Verlag Mueller, Karlsruhe 